\title{
Geburtsweg stellt Weiche für bakterielle Erstbesiedelung des Darms
}

\begin{abstract}
Ob es vaginal oder operativ entbunden wurde, bestimmt die Zusammensetzung der primären Darmflora des Kindes. Einer Studie zufolge sind die Unterschiede allerdings nur innerhalb des ersten Lebensjahres erkennbar.
\end{abstract}

\begin{abstract}
S chon länger wird über das erhöhte Risiko für immunvermittelte Krankheiten bei Kaiserschnittkindern diskutiert. Einer Hypothese zufolge könnte die Art der frühen bakteriellen Kolonisation Einfluss auf die Reifung des Immunsystems haben. Bei Kindern, die bei ihrer Geburt nicht der natürlichen Vaginalflora der Mutter, sondern deren Haut- und Umgebungskeimen ausgesetzt waren, könnte das Asthma, Allergien und andere Erkrankungen des Immunsystems begünstigen. Wie sich verschiedene Geburtswege auf die Kolonisationsmuster in Darm und Atemwegen auswirken, haben dänische Ärzte an 700 Kindern untersucht. Von Diesen wurden mehrfach bakteriologische Kulturen von Stuhlproben und Aspiraten des Hypopharynx angelegt.

$78 \%$ der Kinder waren auf natürlichem Weg zur Welt gekommen, $12 \%$ per Not-
\end{abstract}

kaiserschnitt und $9 \%$ durch geplante Sectio. Alle Mütter der Kaiserschnittbabys hatten Antibiotika erhalten, von den vaginal entbundenen Babys nur $13 \%$. Nach der ersten Lebenswoche wurden in den Stuhlkulturen der Sectiokinder signifikant gehäuft Citrobacter freundii (adjustierte Odds Ratio, aOR:2,78), Clostridien (aOR: 1,82), Enterobacter cloacae (aOR: 2,03), Enterococcus faecalis (aOR: 3,37), Klebsiella oxytoca (aOR: 3,0) und Klebsiella pneumoniae (aOR: 2,44$)$ sowie Staphylococcus aureus (aOR 1,75) festgestellt. Dafür traf man im Vergleich zu vaginal geborenen Kindern weitaus seltener Escherichia coli (aOR: 0,18) an. Nach dem ersten Lebensmonat ließen diese Unterschiede nach, nur Clostridien und Klebsiellen waren noch signifikant häufiger vertreten und E. coli war unterrepräsentiert. Mit einem Jahr waren die Unter- schiede kaum mehr erkennbar. Aber auch die Art des Kaiserschnittes scheint Einfluss zu haben. Während sich nach einem Notkaiserschnitt vermehrt Citrobacter freundii, S. aureus und S. epidermidis fanden, kamen diese bei geplanter Schnittund vaginaler Entbindung etwa gleich häufig vor. Der Vergleich antibiotikabehandelter Frauen beider Gruppen zeigte, dass die Antibiotika offenbar für einen Teil der Unterschiede verantwortlich waren. Keinen Einfluss nach der ersten Lebenswoche hatte der Geburtsweg auf das Mikrobiom der Atemwege.

Fazit: Eine Kaiserschnittgeburt hat Auswirkungen auf die früheste Besiedelung des kindlichen Darms, nicht aber auf das Mikrobiom des Respirationstrakts. Innerhalb des ersten Lebensjahres gleichen sich die Darmbesiedelungen der Kinder an. Sofern ein kausaler Zusammenhang bestehe, könne in diesem Zeitraum der Grundstein für immunvermittelte Krankheiten wie Allergien gelegt werden.

Dr. Christine Starostzik

Stokholm J et al. Cesarean section changes neonatal gut colonization. Allergy Clin Immunol 2016; 138: 881-9

\section{Lässt sich die Spreu bald vom Weizen trennen?}

\section{Bislang fehlen geeignete objektive Marker zur Diagnostik einer Nicht-Zöliakie-Gluten-Sensitivität (NCGS) (siehe dazu auch Allergo Journal 5/2016). Doch daran könnte sich womöglich bald etwas ändern.}

NCGS-Betroffenen zu $60 \%$ keine histologischen Veränderungen und $\mathrm{zu} 40 \%$ Marsh 1 zeigten. Auch die klassischen Marker zur Diagnose einer Zöliakie (IgAAntikörper gegen Gewebstransglutaminase sowie IgG- und IgA-Antikörper gegen deamidiertes Gliadin) waren nur bei Zöliakiepatienten signifikant erhöht, was für einen deutlich unterschiedlichen $\mathrm{Pa}$ thomechanismus spricht.

Die auffällige Antikörperantwort von NCGS-Betroffenen auf natives Gliadin vor allem IgM und IgG - werten die Autoren als Konsequenz einer defekten Darmbarriere. In Annahme einer solchen unterstellten sie eine gestörte Interaktion zwischen der Darmmikrobiota und dem Wirtsorganismus mit einer daraus resultierende Immunaktivierung. Um diesem Verdacht nachzugehen, bestimmten sie Lipopolysaccharid(LPS)bindendes Protein (LBP) und lösliches CD14 (sCD14) als Indikatoren einer Translokation von mikrobiellen Produkten wie LPS. Beide Parameter waren bei NCGS-Betroffenen im Vergleich zu Zöliakiepatienten und Gesunden signifikant erhöht, was als Aktivierung des angeborenen Immunsystems gewertet wurde.

Um die vermutete gestörte Darmbarriere nachzuweisen, wurde Fettsäure-bindendes Protein 2 (FABP2) bestimmt, ein Protein des Zytosols der intestinalen Epithelzellen, das nach einem Zellschaden schnell im Blutkreislauf auftaucht. FABP2 war sowohl bei Zöliakiepatienten als auch bei NCGS-Betroffenen erhöht und korrelierte bei Letzteren mit den LBP- und sCD14-Werten. Warum trotz des über FABP2 nachgewiesenen Epithelschadens weder eine Zottenatrophie noch Verän- 